Abdulkerim Bayülgen $\odot$

Mustafa Azizoğlu $\odot$

Sungur Selim Sinan $\odot$

Erhan Ayan 1

Davud Yapıcı ๑

Mehmet Oğuz Köksel ๑

\title{
Efficacy of Epidural Morphine and Paravertebral Catheter in Post Thoracotomy Pain
}

Etik Kurul Onayı: Mersin Üniversitesi Rektörlüğü Klinik Araştımalar Etik Kurulu’ndan onay alınmıştı (2019/170, 17.04.2019).

Çıkar çatışması: Yazarlar arası çıkar çatışması yoktur.

Finansal destek: Çalışma için herhangi bir finansal destek alınmamıştır.

Hasta onamı: Çalışmamız retrospektiftir.
Ethics Committee: Approval was obtained from Mersin University Rectorate Clinical Research Ethics Committee (2019/170, 17.04.2019)

Conflict of interest: There is no conflict of interest between the authors.

Funding: No financial support has been received for the study.

Informed consent: Our study is retrospective.

Cite as: Bayülgen A, Azizoğlu M, Sinan SS, Ayan E, Yapıcı D, Köksel MO. Epidural morfin ve paravertebral kateter uygulamasının torakotomi sonrası ağrıda etkinliği. GKDA Derg. 2020;26(2):55-61.

\section{öz}

Amaç: Post torakotomi ağrısında kullanılan yöntemlerden olan paravertebral kateter ile epidural kateterin etkinliklerinin karşılaştırılması.

Yöntem: Kliniğimizde Ocak 2013-Ocak 2014 arasında torakotomi uygulanan ve çalıșmaya dahil etme kriterlerine uyan 34 epidural kateter ve 32 paravertebral kateter uygulanan toplam 66 hastanın dosyaları retrospektif olarak değerlendirildi. Hastaların post op 0., 1., 4., 12. ve 24. saatlerdeki nabız, tansiyon, solunum sayısı, parmak saturasyonu, hem istirahat halinde hemde öksürük sırasındaki ağrı düzeyleri açısından Verbal Rating Scale (VRS) değerleri kaydedildi. Toraks dren çekilme zamanları kaydedildi. Gelişen komplikasyonlar zamanları ile kaydedildi.

Bulgular: Her iki grup arasında yaș, cinsiyet, boy ve kilo dağılımı açısından istatistiksel anlamlı farklılık saptanmadı. Saatlik takipler göz önüne alındığında iki grup arasında istatistiki olarak anlamlı farklılık olmadığı görüldü. Her iki gruptada ilk ek analjezik yapılma süresi arasında istatistiksel anlamlı bir farklılık saptanmadı. Her iki grup arasında komplikasyonlar açısından istatistiksel anlamlı bir farklılk saptanmadı.

Sonuç: Paravertebral blok ile epidural kateter etkinlikleri arasında anlamlı farklılık olmaması, paravertebral blok uygulanmasının daha az komplikasyonu olması, daha güvenilir bir şekilde uygulanabilmesi ve etkin analjezi sağlanması nedeni ile epidural blok uygulamasına alternatif bir yöntem olduğunu göstermektedir.

Anahtar kelimeler: paravertebral blok, epidural blok, post torakotomi ağrı

\section{ABSTRACT}

Objective: To compare the efficacy of paravertebral and epidural catheterization techniques which are used in post thoracotomy pain.

Method: The records of 66 patients who underwent epidural $(n=34)$ or paravertebral $(n=32)$ catheterization and thoracotomy between January 2013 and January 2014 were evaluated retrospectively. Verbal Rating Scale (VRS) values and heart rate, blood pressure, respiratory rate, finger $\mathrm{O}_{2}$ saturation, severity of pain at rest and during cough at postoperative 0., 1., 4., 12. and 24. hours were recorded. Thoracic drain withdrawal times were recorded. Complications developed were recorded for each time point.

Results: There was no statistically significant difference between the two groups in terms of age, sex, height and weight distribution. Considering hourly follow-ups, there were no statistically significant difference between the two groups. There was no statistically significant difference between both groups regarding the duration of the first additional analgesic administration, and complications.

Conclusion: Since there is no significant difference between efficacies of paravertebral block and epidural catheterization, paravertebral block application can be an alternative method to epidural block because of lower number of complications, more reliable application and effective analgesia.
Received: 11 December 2019 Accepted: 27 May 2020 Publication date: 30 June 2020

M. Azizoğlu 0000-0002-8266-5203 D. Yapıcı 0000-0003-0169-4182 Mersin Üniversitesi Tıp Fakültesi, Anesteziyoloji ve Reanimasyon Anabilim Dal Mersin - Türkiye

S. S. Sinan 0000-0001-9888-1974 E. Ayan 0000-0003-1889-4404

M. O. Köksel 0000-0002-4340-9725 Mersin Üniversitesi Tıp Fakültesi Hastanesi Göğüs Cerrahisi Anabilim Dalı Mersin - Türkiye

${ }^{\S}$ Bu çalışma 25-28 Nisan 2019 tarihlerinde düzenlenen 10. Ulusal Göğüs Cerrahisi Kongresinde sözel bildiri olarak sunulmuştur.

Keywords: paravertebral block, epidural block, post thoracotomy pain 


\section{Giriş}

Torakotomi ve torakoskopi sonrası ağrı hastanın solunum fonksiyonlarını bozabilir, iyileşmesini geciktirebilir ve strese neden olabilir ${ }^{[1]}$. Torakotominin multipl kas katmanlarını içeren ve kosta yaralanması olasılığı olan bir insizyon olması nedeniyle post torakotomi ağıı bir cerrahi işlem ile ilişkili olarak bilinen en ağrılı durumlardan birisidir ${ }^{[2-6]}$.

Post torakotomi ağrısı artmış morbidite ve mortalite ile ilişkili olabilecek zorlu ve sık görülen klinik bir tablodur ${ }^{[5,7]}$. Daha önceki çalışmalar etkin olmayan analjezinin hipoksi, atelektazi, mukus tıkaçları ve akciğer enfeksiyonları gibi komplikasyonların gelişmesine neden olabileceğini ve post torakotomi ağrı sendromuna yol açabileceğini göstermiş̧ir ${ }^{[6-9]}$.

Post torakotomi ağrısının kesilmesinde etkili, güvenilir bir yöntem olması ve pulmoner komplikasyonları azalttığının gösterilmiş olması nedeni ile en sık kullanılan ve altın standart olarak kabul gören yöntem torasik epidural analjezidir ${ }^{[1,2,4,5,8,10-12]}$. Ancak her ne kadar epidural analjezi altın standart olarak kabul görse de ciddi bir klinik tecrübe gerektirmesi dışında antiagregan tedavi altında, uygulama sahasındaki lokal enfeksiyon durumunda kontrendikedir. Bu yönteme bağlı ciddi komplikasyonlar (spinal kord hasarı, dura perforasyonu, hematom gelişmesine bağlı spinal kord hasarı, menenjit, hipotansiyon, bulantı, kusma, üriner retansiyon, nadiren parapleji) gelişebilir, spinal kord hasar riski nedeni ile hasta tarafından kabul edilmeyebilir veya uygulanması herhangi bir sebeple mümkün olmayabilir ${ }^{[1,5,9-13]}$. Torasik epidural analjezi uygulanan 2907 göğüs cerrahisi hastasının alındığı bir çalışmada, 1 hastada cerrahi girişim gerektirecek epidural hematom ve medikal tedavi edilen 2 hastada epidural abse olmak üzere 3 major komplikasyon geliştiği bildirilmiş olup, 1260000 spinal ve 450000 epidural blok uygulanan hastadan oluşan bir başka çalışmada ise 85 hastada kalıcı nörolojik hasar olmak üzere 127 hastada ciddi nörolojik komplikasyon geliştiği bildirilmiştir [14,15]. Başarısızlık oranı ise 25000 hastalık bir çalışmada \%32 olarak saptanmıştır ${ }^{[16]}$. Ayrıca epidural kateterden uygulanan morfine bağı kaşıntı, bulantı ve kusma, üriner retansiyon, solunum depresyonu gibi yan etkilerde görülebilmektedir ${ }^{[17]}$.

Torasik Paravertebral blok (PVB), tek taraflı abdominal ve torasik cerrahiler için alternatif bir analjezi yöntemidir ${ }^{[1,18]}$. Uygulaması göreceli olarak kolaydır ${ }^{[1,19]}$. PVB tek doz uygulama veya kateter yerleştirilmesi şeklinde uygulanabilmektedir ${ }^{[1,12,18,20]}$. Tek doz uygulamalarda blok işlemi etkin olsa dahi ilk 6 saatten sonra etkisi sonlanmaktadır. Kateter yerleştirilmesi durumunda ise kateter birkaç gün kalarak ek ilaç yapılabilmesi veya infüzyon uygulanabilmesini sağlamaktadır ${ }^{[12,20]}$. Kanıtlar paravertebral bloğun post torakotomi ağrı kontrolünde epidural analjezi kadar etkin olabilen ve epidurale göre daha az yan etkisi olan bir yöntem olabileceğini göstermektedir $[1,2,5,9,11,18,20]$. Plevranın delinmesi, hipotansiyon, pulmoner hemoraji, dura zedelenmesi, hipotansiyon, sinir hasarı ve santral sinir sistemi lokal anestezik toksisitesi bildirilen komplikasyonları arasındadır. Uygulama bölgesinde lokal enfeksiyon, lokal analjezik alerjisi ve işlem yapılacak olan paravertebral alanda tümör bulunması paravertebral bloğun kontrendikasyonlarıdır ${ }^{[21,22]}$. Operasyon öncesi ultrason yardımıyla yerleştirilmesinin yanında, torakotomi sonrası direk görerek başarılı ve güvenli bir şekilde yerleştirilebilmektedir ${ }^{[1,20,21,23]}$.

Yapılan çalışmalarda paravertebral bloğun torakal epidural kateter ile karşılaştırılmasında ağrı skorları ve ek analjezik gereksinimleri açısından karşılaştırılabilir olduğu gösterilmiştir. Kantitatif analizler paravertebral bloğun torakal epidural katetere göre hipotansiyon olasılığını ve pulmoner komplikasyonları azalttığı bildirilmiştir ${ }^{[9]}$. Paravertebral blok uygulanan 319 erişkin hastanın karşılaştıııldığı bir çalışmada blok başarısızlığı \%10,7 olarak bildirilmişken, komplikasyonlardan plevral delinmenin $\% 0,9$, hipotansiyonun $\% 5$ ve vasküler yaralanmanın $\% 3,8$ oranında saptandığı belirtilmiştir ${ }^{[24]}$.

Çalışmamızda, Ocak 2013-Ocak 2014 tarihleri arasın- 
da torakotomi uygulanan hastalarda, torakotomi sonrası ağrıda, cerrahi sırasında takılan paravertebral kateterin, lomber epidural morfin uygulamasına üstünlüğünün olup olmadığının araştırılması amaçlanmıştır.

\section{GEREÇ ve YÖNTEM}

Çalışma için Mersin Üniversitesi Rektörlüğü Klinik Araştırmalar Etik Kurulu'ndan onay alınmıştır. Kliniğimizde Ocak 2013-Ocak 2014 tarihleri arasında torakotomi uygulanan, $18-80$ yaş aralığında, acil cerrahi girişim yapılmayan, başka bölümün operasyona dahil olmadığı, operasyon sırasında komplikasyon gözlenmeyen ve reoperasyon gerekmeyen hastalar çalışma kapsamına alınmıştır. Bu kriterlere uyan hastaların dosyaları geriye dönük olarak taranmış; torakotomi operasyonu geçirmiş, lomber epidural ve cerrahi sırasında paravertebral kateter uygulanan 66 hastanın kayıtlarına tam olarak ulaşılmıştır. Bu hastalardan 34 tanesine lomber epidural kateter (Grup Ep) uygulanmışken, 32 tanesine cerrahi sırasında paravertebral kateter (Grup Pv) uygulanmıştır. Hastaların operasyonlarına aynı cerrahi ve anestezi ekibi dahil olmuştur.

Kliniğimizde rutin uygulama olarak; torakotomi geçirecek hastalara anestezi indüksiyonu ve entübasyon sonrası uygun pozisyon verilerek lomber bölgeden epidural kateter uygulanmakta, postoperatif analjezi için $4 \mathrm{mg}$ Morfin/10 mL serum fizyolojik içinde sulandırılarak yapılmaktadır. Epidural kateter uygulanamayan hastalara, operasyon bitiminde, toraks kapanmadan önce, cerrah tarafından insizyon hattına uyan vertebral seviyeden, paravertebral kateter yerleştirilmekte ve yine cerrahi ekip tarafından $10 \mathrm{~mL} \%$ 0,5 Bupivacain, $8 \mathrm{~mL}$ Serum fizyolojik ve $2 \mathrm{~mL}$ Fentanyl uygulanmaktadır. Ayrıca bütün hastalara cerrahi sonrasında rutin olarak intramusküler non-steroid anti enflamatuar ilaç (diclofenac, $75 \mathrm{mg}$ ) günde $2 \mathrm{doz}$ olarak verilmektedir.

Hastaların dosyalarından; ASA (Amerikan Anesteziyoloji Derneği fiziksel durum skoru) skorları, postoperatif $0,1,4,12$ ve 24 . saatlerdeki kalp hızı, kan basıncı, solunum sayısı, parmak ucu saturasyonu kaydedildi. Hem istirahat halinde hem de öksürük sırasındaki ağrı düzeyleri açısından Verbal Rating Scale (VRS) değerleri kaydedildi. VRS hastaların vizüel analog skalaya (VAS) yanıtlarına göre hesaplanmıştır. Buna göre VAS 1-3 arası VRS 1 (hafif ağrı), VAS 3-5 arası VRS 2 (orta derecede ağrı), VAS 5-7 arası VRS 3 (şiddetli ağrı) ve VAS 7-10 olanlar VRS 4 (ızdıraplı ağrı) olarak değerlendirildi ${ }^{[25]}$. Hastaların anestezi sonrası derlenme durumları, Modifiye Aldrete Skorlama sistemiyle ${ }^{[26]}$ yapılmakta ve kayıt altına alınmaktadır. Hastalar postoperatif 1. günde monitörize şekilde ara yoğun bakımda takip edilmektedir.

Hastaların peroperatif ve postoperatif 1. gün sıvı balansları sırasıyla anestezi kayıt fişleri ve servis hasta izlem kayıtlarından kaydedilmiştir. Ayrıca servis hasta izlem kayıtlarından toraks dren çekilme zamanları, ilk ilave analjezik uygulama zamanı ve gelişen komplikasyonlar günlük olarak kaydedildi.

İstatistiksel analizler SPSS 21 (IBM) programı ile yapımıştır. Sürekli olanlarda t testi kullanılırken, kategorik değişkenlerin analizi ki kare testi ile yapılmıştır.

\section{BULGULAR}

Toplam 66 hastanın kayıtlarına tam olarak ulaşıldı. Hastalar lomber epidural (Grup Ep,n=34) ve cerrahi sırasında paravertebral kateter uygulanan (Grup Pv, n=32) olmak üzere iki gruba ayrıldı.

Grup Pv'de yaş ortalaması 55,59 iken Grup Ep'de 53,35 olarak bulundu ve iki grup arasında istatistiksel farklılık saptanmadı ( $p=0.47)$. Gruplar arası ASA skorlarına bakıldığında; Grup Pv'de 16 (\%50) ve Grup Ep'de 20 kişinin $(\% 58,8)$ ASA III olduğu gözlendi ve gruplar arası farklılık gözlenmedi (Tablo 1). Cerrahi süreleri karşılaştırıldığında, paravertebral uygulanan grupta 193,12 dk iken epidural morfin grubunda 219,70 dk olarak saptanmış olup her iki grup arasında anlamlı farklılık bulunmamıştır $(p=0.18)$. Hastaların peroperatif sıvı balansları karşılaştırıldığında, epidural morfin grubunda Grup Pv'de 794,37 $\mathrm{mL}$, Grup Ep'de ise 1058,82 ml olarak saptanmış ve 
Tablo 1. Grupların ASA skorları.

\begin{tabular}{|c|c|c|c|c|}
\hline & & Grup Pv & Grup Ep & Toplam \\
\hline \multirow{4}{*}{ 蒾 } & I & $1(\% 3,1)$ & $1(\% 2,9)$ & $2(\% 3,0)$ \\
\hline & II & $13(\% 40,6)$ & $11(\% 32,4)$ & $24(\% 36,4)$ \\
\hline & III & $16(\% 50,0)$ & $20(\% 58,8)$ & $36(\% 54,5)$ \\
\hline & IV & $2(\% 6,3)$ & $2(\% 5,9)$ & $4(\% 6,1)$ \\
\hline
\end{tabular}

ASA: American Society of Anesthesiologists

bu fark istatistiksel olarak anlamlıydı $(p=0.02)$. Postoperatif 1. gün sıvı balansları arasında istatistiksel bir fark tespit edilmemiştir ( $p=0.14$ ) (Tablo 2).

Aldrete derlenme skorları; paravertebral uygulanan grupta; 0. dakikada 9,09 iken, 5. dakikada 9,75, epidural morfin uygulanan grupta ise 0 . dakikada 8,70 iken 5. dakikada 9,79 olarak bulunmuştur ( $p$ değerleri sırasıyla, 0,07 ve 0,71 ) (Tablo 2 ).

Dren çekilme zamanı; Pv grubunda ortalama 7,28 gün, Ep grubunda ise ortalama 7,73 gün olarak bulunmuş olup her iki grup arasında anlamlı farklılık saptanmamıştır ( $p=0.75$ ) (Tablo 2).

Her iki grubun istirahatte bakılan ağrı skorlarında (iVRS) bütün ölçümlerde orta derecenin üzerinde ağrı olmadığı görülmüş ve bu değerler istatistiksel olarak anlamlı bulunmamıştır (Şekil 1). Her iki grupta öksürük sırasında kaydedilen ağrı skorları (öVRS) arasında da istatistiksel anlamlı farklılık saptanmamıştır (Şekil 2). Her iki grupta da ortalama 5. saatte ilk ek analjezik uygulanmıştır ve gruplar arasında istatistiksel anlamlı bir fark bulunmamıştır ( $p=0.83$ ) (Tablo 2 ).

Çalışmada komplikasyonlara bakıldığında; postoperatif 1. günde Grup Ep'de 2 ve Grup Pv'de 1 hastada hipotansiyon saptanmıştır. Her iki grup arasında komplikasyonlar açısından istatistiksel anlamlı bir farklıık saptanmamıştır $(p=0.51)$.

\section{TARTIŞMA}

Bu çalışma cerrahi sırasında, görerek yerleştirilen paravertebral kateter uygulamasının, torakotomi sonrası ağrı skorları göz önüne alındığında, lomber
Tablo 2. Her iki grup arasındaki operatif ve postoperatif bulgular.

\begin{tabular}{lccc} 
& Grup Pv & Grup Ep & p \\
\hline Cerrahi Süresi (dk) & 193,12 & 219,70 & 0,18 \\
Peroperatif Balans (ml) & 794,37 & 1058,82 & 0,02 \\
Postoperatif 1. gün Balans (ml) & 363,12 & 582,94 & 0,14 \\
Dren Çekim Zamanı (gün) & 7,28 & 7,73 & 0,75 \\
ilk Ek Analjezik Saati & 5,56 & 5,32 & 0,83 \\
Aldrete Skoru (0. dk) & 9,09 & 8,70 & 0,07 \\
Aldrete Skoru (5. dk) & 9,75 & 9,79 & 0,71
\end{tabular}

Grupların ortalama değerleri verilmiştir. $P<0,05$ anlamlı olarak kabul edilmiştir.

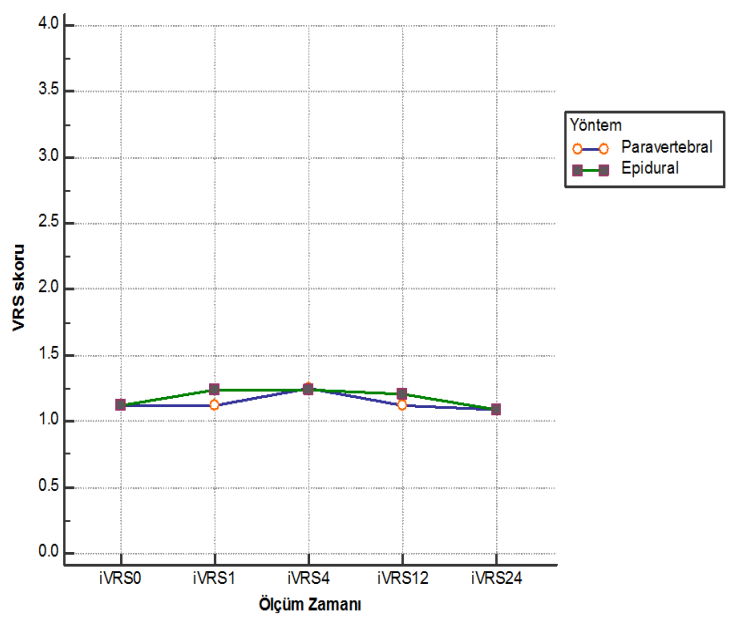

Şekil 1. İstirahat dönemi ağrı skorları. iVRS: istirahat Verbal Rating Scale.

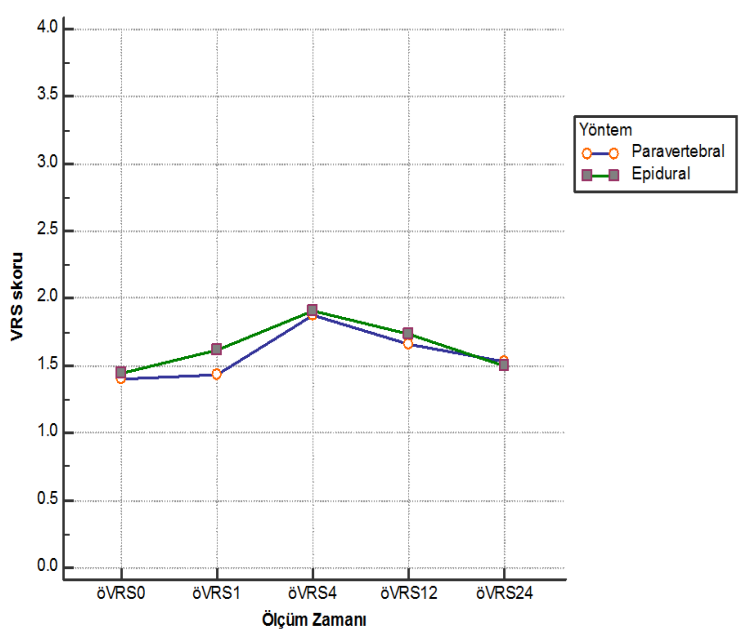

Şekil 2: Öksürük sırasındaki ağıı skorları. öVRS: öksürük Verbal Rating Scale. 
epidural morfin uygulaması kadar etkili olduğunu ve ilave bir komplikasyona neden olmadan güvenli bir şekilde uygulanabilineceğini göstermiştir.

Richardson ve ark.'nın ${ }^{[27]}$ prospektif randomize olarak gerçekleştirdikleri, torakal epidural ve paravertebral bupivakain uygulamasının torakotomi sonrası ağrı, pulmoner fonksiyonlar ve stres yanıtları üzerine etkisinin değerlendirildiği bir çalışmada; paravertebral uygulanan hastalarda, torakal epidural uygulananlara göre hem istirahat hem de öksürük sırasındaki ağrı skorlarının daha düşük ve morfin kullanımının daha az olduğu rapor edilmiştir. Dango ve ark.'nın [5] 84 hasta ile yaptığı başka bir prospektif randomize çalışmada ise torasik epidural analjezi (ropivakain + sulfentanil) ile paravertebral blok (ropivakain) ve intratekal opioid (sulfentanil + morfin) uygulamasının etkinlikleri araştırılmıştır. Hastaların istirahat ve öksürük anındaki ağrı düzeyleri karşılaştıııımış ve torakal epiduralin, paravertebral ile birlikte uygulanan intratekal opioide göre daha iyi bir analjezi sağlasa da bunun klinik olarak anlamlı olmadığı ve paravertebral uygulamanın torasik epidurale bir alternatif olduğu rapor edilmiştir. Yapılan başka çalışmalarda ise paravertebral bloğun epidural kadar etkin olduğu hatta bazı çalışmalarda ilk 24 saatte epidural uygulamadan daha üstün analjezik etkinlik gösterdiği bildirilmiştir ${ }^{[13,27,28]}$. Aynı zamanda pulmoner fonksiyonlar, nöroendokrin stres yanıtı ve yan etki profili açısından daha güvenilir bir yöntem olduğu bildirilmiştir ${ }^{[13,27]}$. Lomber epidural morfin uygulanan hastaların, cerrahi sırasında takılan paravertebral kateterin karşılaştırıldığı çalışmamızda, torakotomi uygulanan hastalarda operasyon sonrası ağrı skorlarının benzer olduğu gözlenmiştir. Paravertebral kateter uygulamasının lomber epidural morfin uygulaması kadar etkin olduğu bulunmuştur.

Her iki grup arasında dren çekme zamanları arasında istatistiksel anlamlı farklılık saptanmamıştır. Bu durumunda her iki grubun karşılaştırmasını bozmadığını düşünmekteyiz.

Torakotomi sonrası analjezi için kullanılmakta olan epidural kateterden morfin uygulamasında; bulantı (\%22), kaşıntı (\%22) ve hipotansiyon (\%3) gibi yan etkiler görülebilmektedir ${ }^{[29]}$. Pnömonektomi sonrası paravertebral blok ile torakal epidural analjezik uygulamasının etkinliklerinin araştıııldığı prospektif bir çalışmada major komplikasyon insidansının torakal epidural grupta daha fazla olduğu rapor edilmiştir. Gelişen bu major komplikasyonlar arasından inotrop desteği gerektiren hipotansiyon epidural ile ilişkili komplikasyon olarak tanımlanmıştır ${ }^{[30]}$. Davies ve ark yayınladıkları, göğüs cerrahisi operasyonu geçiren 520 hastayı içeren ve 10 randomize kontrollü çalışmayı içeren bir meta analizde, paravertebral ve epidural analjezik etkinlikleri ve yan etkilerini araştırılmıştır ${ }^{[13]}$. Epidural uygulanan grupta artmış hipotansiyon, üriner retansiyon, bulantı-kusma ve pulmoner komplikasyonlar saptanmıştır. Ayrıca paravertebral uygulanan grupta başarı oranının daha fazla olduğu rapor edilmiştir. Paravertebral uygulamalarda da epidural kateter uygulamalarında olduğu gibi hipotansiyon, pulmoner hemoraji, dura zedelenmesi, sinir hasarı gibi komplikasyonlar gözlenebilmektedir ancak görülme oranları epidural uygulamasına göre daha düşüktür ${ }^{[1,4,18,19]}$. Paravertebral uygulamada tek tarafIı blok oluştuğundan, hipotansiyon gelişiminin daha az olacağı beklenmektedir ${ }^{[30]}$. Çalışmamızda paravertebral uygulanan 1 epidural uygulanan 2 hastada hipotansiyon gelişmiş olup bunun dışında analjezi yöntemine bağlı komplikasyon gözlenmemiştir ve her iki grup arasında komplikasyonlar açısından anlamlı farklılık saptanmamıştır. Bunun nedeninin çalışmamızdaki hasta sayısının azlığına bağlı olduğun ve daha geniş serili çalışmalar yapılması gerektiğini düşünmekteyiz. Epidural morfin uygulamalarına bağlı gelişen ve en ciddi komplikasyon olarak belirtilen geç solunum depresyonu hiçbir hastada gözlenmemiştir [29]. Hastaların postoperatif nerede takip edileceğinin belirlenmesi için yapılan bir çalışmada, epidural uygulanan hastalar, paravertebral ile karşılaştırıldığında, postoperatif dönemde daha fazla yoğun bakım intiyacı olduğu saptanmıştır ${ }^{[30]}$. Bu yüzden Epidural ilişkili komplikasyonlar açısından hastaların postoperatif dönemde daha yakın ve monitörize bir şekilde takibe intiyaç duydukları belirtilmektedir ${ }^{[2]}$. 
Hastalar arasındaki farklı vertebral anatomi, epidural uygulama tekniğini daha da zor hale getirebilir ve hem komplikasyon hem de başarı şansını etkileyebilir ${ }^{[2]}$. Paravertebral kateter anestezi altındaki hastada toraks açıkken görerek ve güvenle yerleştirilebilir $[1,2,4,18,19,31,32]$. Bu durum paravertebral uygulama için bir avantaj oluşturmaktadır ${ }^{[2]}$. Kliniğimizde epidural uygulamanın yapılamadığı hastalarda eğer uygun ise, operasyon bitiminde toraks kapanmadan, cerrahi ekip tarafından paravertebral kateter uygulanabilmektedir. Paravertebral kateter ile ilgili yapılan çalışmalarda torasik epidural ve IV analjezi teknikleri ile karşılaştıııldığında, daha güvenli olması, daha iyi yan etki profili ile karşılaştırılabilir analjezi sağlaması sebebi ile kullanımı önerilmektedir [4,13,18,19] . Dekortikasyon, parietal plevranın serbestlenmesi ve torakotomi insizyonunun posteriora doğru çok uzatılması durumları, paravertebral kateter uygulanmasının kısıtlılıkları arasında yer alsa da, torakotomi uygulanmış hastalarda cerrah veya anestezi ekibi tarafından, görerek yerleştirilebilir olması bir üstünlük olarak değerlendirilebilir.

Akciğer kanseri nedeni ile pnömonektomi uygulanan hastalarda sıvı kısıtlamasının önemi bilinmektedir. Bu konu ile ilgili yapılan ve epidural blok ile paravertebral kateter uygulamasının karşılaştıııldığı çok merkezli bir çalışmada; epidural kateter grubunda postoperatif ilk 24 saatte ki sıvı balansının daha düşük olduğu belirtilmiştir ${ }^{[30]}$. Çalışmamızda operasyon süreleri benzer olmasına rağmen, perioperatif dönemdeki sıvı balansının paravertebral uygulanan hastalarda epidural morfine göre daha az olduğu saptanmıştır. Fakat bu farkın klinik olarak anlamlı olmadığı kanısındayız. Gruplar arasında postoperatif 1. gün sıvı balansları da benzer olarak bulunmuştur. Çalışmamızda hastaların postoperatif derlenme skorları açısından da anlamlı bir farklııı̆ın olmadığı gözlenmiştir.

Çalışmamızın retrospektif olması ve denek sayısının azlığı limitasyon olarak değerlendirilmiştir. Bu yüzden iki analjezi yönteminin karşılaştırıldığı prospektif randomize ve geniş serili çalışmalara gereksinim vardır. Sonuç olarak torakotomi sırasında görerek uygula- nan paravertebral kateter, lomber epidural kateterden uygulanan morfin ile aynı düzeyde analjezi sağlamıştır. Etkin analjezi sağlaması, daha kolay ve daha güvenli bir şekilde uygulanabilmesi ve daha az komplikasyon gözlenmesi nedeni ile paravertebral kateterin, lombar epidural morfin uygulanmasına alternatif bir yöntem olabileceği kanısındayız.

\section{KAYNAKLAR}

1. Myles PS, Bain C. Underutilization of paravertebral block in thoracic surgery. J Cardiothorac and Vasc Anesth. 2006;20(5):635-8. https://doi.org/10.1053/j.jvca.2006.06.007

2. Elsayed H, McKevith J, McShane J, Scawn N. Thoracic epidural or paravertebral catheter for analgesia after lung resection: Is the outcome different? J Cardiothorac and Vasc Anesth. 2012;26(1):78-82. https://doi.org/10.1053/j.jvca.2011.09.019

3. Gerner P. Postthoracotomy pain management problems. Anesthesiology Clin. 2008;26:355-67. https://doi.org/10.1016/j.anclin.2008.01.007

4. Pennefather SH, McKevith J. Pain Management After Thoracic Surgery. In: P. Slinger, ed. Principles and Practice of Anesthesia for Thoracic Surgery. New York: Springer Science+Business Media; 2011. p 675-707. https://doi.org/10.1007/978-1-4419-0184-2_46

5. Dango S, Harris S, Offner K, Hennings E, Priebe H-J, Buerkle $\mathrm{H}$, et al. Combined paravertebral and intrathecal vs thoracic epidural analgesia for post-thoracotomy pain relief. Br J Anaesth. 2013; 110(3):443-9. https://doi.org/10.1093/bja/aes394

6. Zeid HA, Siddiqui AK, Elmakarem EFA, Ghonaimy Y, Al Nafea A. Comparison between intrathecal morphine with paravertebral patient controlled analgesia using bupivacaine for intraoperative and post-thoracotomy pain relief. Saudi J Anaesth. 2012;6(3):201-6. https://doi.org/10.4103/1658-354X.101204

7. Dokhan AL, Elaziz MEA, Gaballah KM. Efficacy of paravertebral block analgesia for post-thoracotomy pain control. Journal of the Egyptian Society of CardioThoracic Surgery. 2016;24:65-72. https://doi.org/10.1016/j.jescts.2016.04.012

8. Sztain JF, Gabriel RA, Said ET. Thoracic Epidurals are Associated With Decreased Opioid Consumption Compared to Surgical Infiltration of Liposomal Bupivacaine Following Video-Assisted Thoracoscopic Surgery for Lobectomy: A Retrospective Cohort Analysis. Journal of Cardiothoracic and Vascular Anesthesia. 2019;33:694-8. https://doi.org/10.1053/j.jvca.2018.06.013

9. Joshi GP, Bonnet F, Shah R, Wilkinson RC, Camu F, Fischer B, et al. A Systematic review of randomized trials evaluating regional techniques for postthoracotomy analgesia. Anesth Analg. 2008;107(3):1026-40. 
https://doi.org/10.1213/ane.0b013e31817e7b40

10. Yeğin A, Erdoğan A, Hadimioğlu N. Toraks cerrahisinde ameliyat sonrası analjezi. Turkish J Thorac Cardiovasc Surg 2005;13(4):418-25.

11. Grider JS, Mullet TW, Saha SP, Harned ME, Sloan PA. A randomized, double-blind trial comparing continuous thoracic epidural bupivacaine with and without opioid in contrast to a continuous paravertebral infusion of bupivacaine for post-thoracotomy pain. Journal of Cardiothoracic and Vascular Anesthesia. 2012;26(1): 83-9. https://doi.org/10.1053/j.jvca.2011.09.003

12. Yeap YL, Wolfe JW, Backfish-White KM, Young JW, Stewart J, Ceppa DP, et al. Randomized prospective study evaluating single- injection paravertebral block, paravertebral catheter, and thoracic epidural catheter for postoperative regional analgesia after video-assisted thoracoscopic surgery. J Cardiothorac and Vasc Anesth. 2020;34(7):1870-6. https://doi.org/10.1053/j.jvca.2020.01.036

13. Davies RG, Myles PS, Graham JM. A comparison of the analgesic efficacy and side-effects of paravertebral vs epidural blockade for thoracotomy-a systematic review and meta-analysis of randomized trials. $\mathrm{Br} \mathrm{J}$ Anaesth. 2006;96(4):418-26.

https://doi.org/10.1093/bja/ael020

14. Kupersztych-Hagege E, Dubuisson E, Szekely B, MichelCherqui M, Dreyfus JF, Fischler M, et al. Epidural hematoma and abscess Related to Thoracic Epidural Analgesia: A Single-Center Study of 2,907 Patients Who Underwent Lung Surgery. Journal of Cardiothoracic and Vascular Anesthesia 2017;31:446-52. https://doi.org/10.1053/j.jvca.2016.07.022

15. Moen V, Dahlgren N, Irestedt L. Severe Neurological Complications after Central Neuraxial Blockades in Sweden 1990-1999. Anesthesiology 2004;101:950-9. https://doi.org/10.1097/00000542-200410000-00021

16. Rawal N. Epidural Technique for Postoperative Pain Gold Standard No More? Reg Anesth Pain Med. 2012;37:310-7. https://doi.org/10.1097/AAP.0b013e31825735c6

17. Chaney MA. Side effects of intrathecal and epidural opioids. Can J Anaesth. 1995;42(10):891-903. https://doi.org/10.1007/BF03011037

18. Piraccini E, Pretto Jr EA, Corso RM, Gambale G. Analgesia for thoracic surgery: the role of paravertebral block. HSR Proceedings in Intensive Care and Cardiovascular Anesthesia 2011;3(3):157-60.

19. Karmakar MK. Thoracic paravertebral block. Anesthesiology 2001;95:771-80. https://doi.org/10.1097/00000542-200109000-00033

20. Fibla JJ, Molins L, Mier JM, Sierra A, Carranza D, Vidal G. The efficacy of paravertebral block using a catheter technique for postoperative analgesia in thoracoscopic surgery: a randomized trial. European Journal of Cardio-thoracic Surgery 2011;40:907-11. https://doi.org/10.1016/j.ejcts.2010.12.043

21. Tighe SQM, Greene MD, Rajadurai N. Paravertebral block. Continuing Education in Anesthesia, Critical Care \& Pain 2010;10(5):133-7. https://doi.org/10.1093/bjaceaccp/mkq029

22. Dodd M, Hunsley J. Thoracic paravertebral block: Landmark techniques anaesthesia tutorial of the week 224. ATOTW 224 - Paravertebral block, Landmark Techniques. Available at: www.frca.co.uk > Documents , 224 Paraver... Accessed February 25, 2020.

23. D'Ercole F, Arora H, Kumar PA. Paravertebral block for thoracic surgery. J Cardiothorac Vasc Anesth. 2018; 32(2): 915-927. https://doi.org/10.1053/j.jvca.2017.10.003

24. Lönnqvist PA, MacKenzie J, Soni AK, Conacher ID. Paravertebral blockade: Failure rate and complications. Anaesthesia 1995;50:813-5. https://doi.org/10.1111/j.1365-2044.1995.tb06148.x

25. Lund I, Lundeberg T, Sandberg L, Budh, CN, Kowalski J, Svensson E. Lack of interchangeability between visual analogue and verbal rating pain scales: a cross sectional description of pain etiology groups. BMC Med Res Methodol. 2005;5:31. https://doi.org/10.1186/1471-2288-5-31

26. Banerjee S, Kohli P, Pandey M. A study of modified Aldrete score and fast-track criteria for assessingrecovery from general anaesthesia after laparoscopic surgery in Indian adults. Perioperative Care and Operating Room Management 2018;12:39-44. https://doi.org/10.1016/j.pcorm.2018.10.001

27. Richardson J, Sabanathan S, Jones J, Shah R, Cheema S, Mearns AJ. A prospective, randomized comparison of preoperative and continuous balanced epidural or paravertebral bupivacaine on post-thoracotomy pain, pulmonary function and stress response. $\mathrm{Br} J$ Anaesth. 1999;83:387-92. https://doi.org/10.1093/bja/83.3.387

28. Kaiser AM, Zollinger A, De Lorenzi D, Largiade'r F, Weder W. Prospective, randomized comparison of extrapleural versus epidural analgesia for postthoracotomy pain. Ann Thorac Surg. 1998;66:367-72. https://doi.org/10.1016/S0003-4975(98)00448-2

29. Kapıcıbaşı HO, Meydan B, Koşar A, Sönmez H, Kır A, Atasalihi A. Torakotomi sonrası ağrı tedavisinde interkostal sinir blokajının etkisi. Toraks Dergisi 2008;9(2):57-9.

30. Powell ES, Cook D, Pearce AC, Davies P, Bowler GMR, Naidu B, et al. A prospectictive, multicentre, observational cohort study of analgesia and outcome after pneumonectomy. Br J Anaesth. 2011;106(3):364-70. https://doi.org/10.1093/bja/aeq379

31. Sabanathan S, Richardson J, Shah R: Continuous intercostal nerve block for pain relief after thoracotomy. Ann Thorac Surg. 1995;59:1261-3. https://doi.org/10.1016/0003-4975(95)00058-S

32. Bimston DN, McGee JP, Liptay MJ, et al: Continuous paravertebral extrapleural infusion for post-thoracotomy pain management. Surgery 1999;126:650-6. https://doi.org/10.1016/S0039-6060(99)70118-2 